\title{
Development of Poly(Lactic Acid) filled with basalt fibres and talc for engineering applications
}

\author{
Tamás Tábi ${ }^{1,2, a}$, Mauro Zarrelli3,b \\ ${ }^{1}$ MTA-BME Research Group for Composite Science and Technology, \\ Muegyetem rkp. 3., $\mathrm{H}-1111$ Budapest, Hungary \\ ${ }^{2}$ Department of Polymer Engineering, Faculty of Mechanical Engineering, Budapest University of \\ Technology and Economics, Muegyetem rkp. 3., H-1111 Budapest, Hungary \\ ${ }^{3}$ Institute of Composite and Biomedical Materials, National Research Council of Italy, \\ 80055, Portici (NA), Italy \\ atabi@pt.bme.hu, ${ }^{b}$ mauro.zarrelli@imcb.cnr.it
}

Keywords: Biocomposites, biodegradable polymers, basalt fibres, talc, Poly(Lactic Acid)

Abstract. The development of renewable resource based and inherently biodegradable polymers as well as their composites are one of the most important research fields nowadays in polymer science. Poly(Lactic Acid) (PLA), as the most promising biodegradable polymer has the potential to replace even engineering composite materials by reinforcing it with natural plant fibres or mineral fibres like basalt. However, one major drawback is its low heat deflection temperature (HDT, $\sim 55^{\circ} \mathrm{C}$ ) caused by its slow crystallization kinetics and thus low crystallinity of the final product. This feature also retards the usage of PLA in composite materials for elevated temperature applications. At the same time, nucleating agents like talc can be used to enhance crystallinity and thus HDT. In this paper basalt fibre reinforced and talc filled PLA composites were prepared by extrusion followed by injection moulding. The results showed that by combining the stiffness increasing effect of basalt fibres as well as the crystallinity increasing effect of talc, a composite with both high mechanical properties and high HDT could be produced.

\section{Introduction}

Nowadays, the usage of renewable resource based and inherently biodegradable polymers are in the focus of interest [1] due to decreasing resources of crude oil and increasing waste management problems caused by short life cycle packaging applications. Currently, the most promising biodegradable polymer is the starch based Poly(Lactic Acid) (PLA) [2], which is an aliphatic, thermoplastic, semi-crystalline polymer, with high strength $(\sim 65 \mathrm{MPa}$ tensile strength) and high stiffness ( $\sim 3 \mathrm{GPa}$ elasticity modulus), but unfortunately with rather low impact strength $\left(\sim 25 \mathrm{~kJ} / \mathrm{m}^{2}\right.$ of Charpy unnotched impact strength) and low heat deflection temperature (HDT, $\sim 55^{\circ} \mathrm{C}$ ). Accordingly, PLA has not only the potential to replace some of the conventional plastics like Polystyrene (PS) or Poly(Ethylene Terephthalate) (PET), but by preparing composites, it may gather ground in mechanically loaded, engineering applications as well [3]. In some of our previous studies, it was already proved that the volcanic rock based basalt fibres [4] are excellent reinforcements for PLA [5-7]. By using 30wt\% of short basalt fibres and the conventional extrusion and injection moulding processing, a basalt fibre reinforced PLA composite with $120 \mathrm{MPa}$ and 180 $\mathrm{MPa}$ of tensile and flexural strength as well as $7.6 \mathrm{GPa}$ and $10.4 \mathrm{GPa}$ of tensile and flexural modulus could be reached respectively, while it was also possible to increase Charpy unnotched impact strength up to $38 \mathrm{~kJ} / \mathrm{m}^{2}$ [5]. Despite the high mechanical properties, the HDT was still low, around $60^{\circ} \mathrm{C}$ for these composites, which is caused by the low glass transition temperature $\left(\mathrm{T}_{\mathrm{g}}\right)$ and the low crystallinity of PLA, since unfortunately, PLA has a very slow crystallization kinetics. This disadvantageous property may be overcome by using additional nucleating agents [8], however, during injection moulding processing of PLA, due to the high cooling rate applied, it is still challenging to develop high level of crystallinity. Talc was already proved to be an effective nucleating agent for PLA $[9,10]$ and may be used to develop high crystallinity during processing 
and thus high HDT. Accordingly, in our work, basalt fibre reinforced and talc filled PLA composites were prepared by extrusion and injection moulding, and the applicability of the prepared composites were investigated for engineering applications.

\section{Experimental}

NatureWorks PLA type 3052D biopolymer was used for the composite preparation. This grade contains $1.4 \%$ of D-Lactide and has a density of $1.24 \mathrm{~g} / \mathrm{cm}^{3}$, a melting temperature of $145-160^{\circ} \mathrm{C}$ and a $\mathrm{T}_{\mathrm{g}}$ of $55-60^{\circ} \mathrm{C}$. Chopped basalt fibres type $\mathrm{KV}-12$ were purchased from Kammeny Vek with a silane treatment. The fibres had a diameter of 10-22 $\mu \mathrm{m}$ and an initial length of $10 \mathrm{~mm}$. Finally, fine particle size talc type HTPUltra5 was purchased from Imifabi with a median diameter of $0.65 \mu \mathrm{m}$.

Prior to compounding, all the materials were dried at $85^{\circ} \mathrm{C}$ for 6 hours. PLA, basalt fibres and talc were compounded with a LabTech LTE 26-44 twin screw extruder equipped with $26 \mathrm{~mm}$ diameter screws. Melt temperature was kept at $190^{\circ} \mathrm{C}$, while the screw rotational speed was set to $201 / \mathrm{min}$. 0, 10, 20 and $30 \mathrm{wt} \%$ of basalt fibres as well as $0,5,10$ and $15 \mathrm{wt} \%$ of talc was used for composite preparation. All of the possible 16 combinations were produced (Table 1.).

\begin{tabular}{|c|c|c|c|c|}
\hline $\begin{array}{c}\text { Talc/Basalt fibre } \\
\text { content [wt\%] }\end{array}$ & 0 & 10 & 20 & 30 \\
\hline 0 & PLA & 10B_0T & 20B_0T & 30B_0T \\
\hline 5 & 0B_5T & 10B_5T & 20B_5T & 30B_5T \\
\hline 10 & 0B_10T & 10B_10T & 20B_10T & 30B_10T \\
\hline 15 & 0B_15T & 10B_15T & 20B_15T & 30B_15T \\
\hline
\end{tabular}

Table 1. Abbreviations of the produced composites

The compounded materials were injection moulded with an Arburg Allrounder 370S 700-290 injection moulding machine equipped with a $35 \mathrm{~mm}$ diameter screw. $190^{\circ} \mathrm{C}$ of melt temperature and $20^{\circ} \mathrm{C}$ of mould temperature was used, but in some cases, the mould temperature was set to $90^{\circ} \mathrm{C}$ to enhance crystallization. Cooling time was set to $60 \mathrm{sec}$. The mechanical (tensile, flexural, impact) and thermal (crystallinity, HDT) properties of the injection moulded composites were investigated by using a Zwick Z020 universal testing machine, a TA Q2000 differential scanning calorimeter (DSC) and a Ceast HV3 6911.000 HDT machine. For the mechanical tests 6 specimens were tested and $\pm 2 \sigma$ standard deviation was represented in the diagrams. Finally, the fracture surface of the specimens was investigated by using a Jeol JSM 6380LA scanning electron microscope (SEM).

\section{Results and discussion}

Our investigation begun with the analysis of the mechanical properties of the composites (Fig. 1-3.). By increasing basalt fibre content, both tensile and flexural strength was found to increase linearly up to $20 \mathrm{wt} \%$, reaching a tensile and flexural strength of $102 \mathrm{MPa}$ and $157 \mathrm{MPa}$ respectively, but above $20 \mathrm{wt} \%$, most probably due to fibre breakage, the gradient of the linear decreased (Fig. 1.).
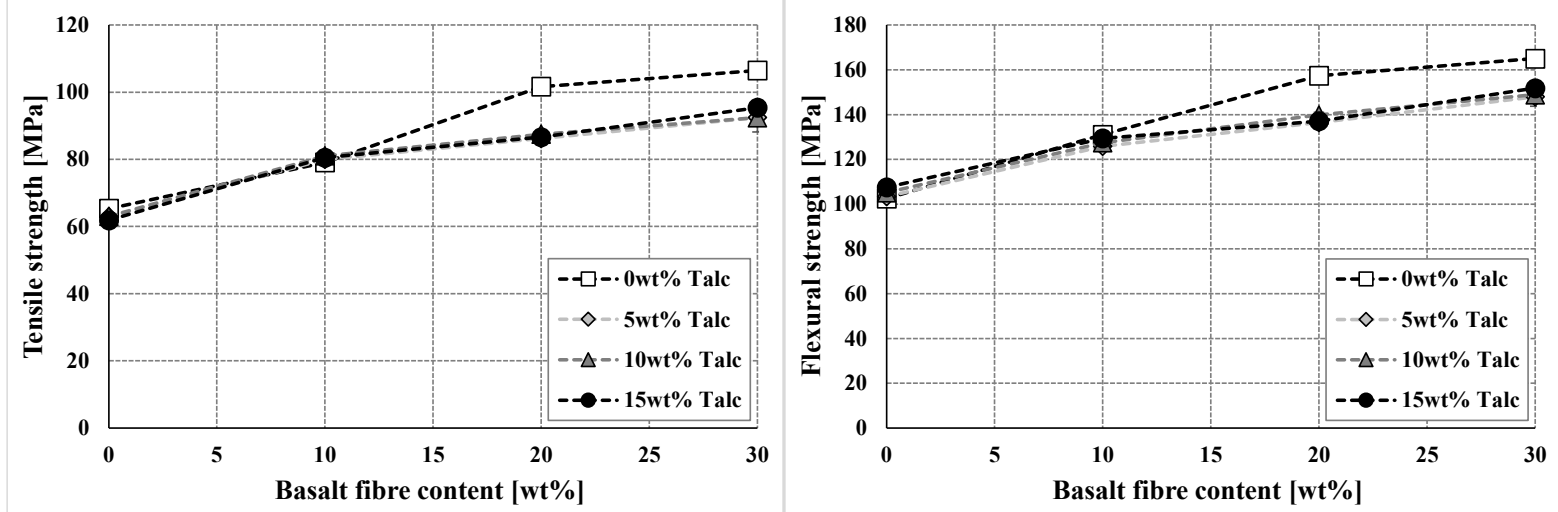

Fig. 1. Tensile (left) and flexural (right) strength of the basalt reinforced and talc filled PLA composites 
When talc was also added to the composites, a negative cross-effect was found, since by increasing basalt fibre content, the gradient of the linear line already started to decrease above $10 \mathrm{wt} \%$. According to the modulus values (Fig. 2.), both basalt and talc increased the tensile and flexural modulus linearly in the investigated $30 \mathrm{wt} \%$ basalt and $15 \mathrm{wt} \%$ talc content range, thus no crosseffect was found between the reinforcement and the filler.
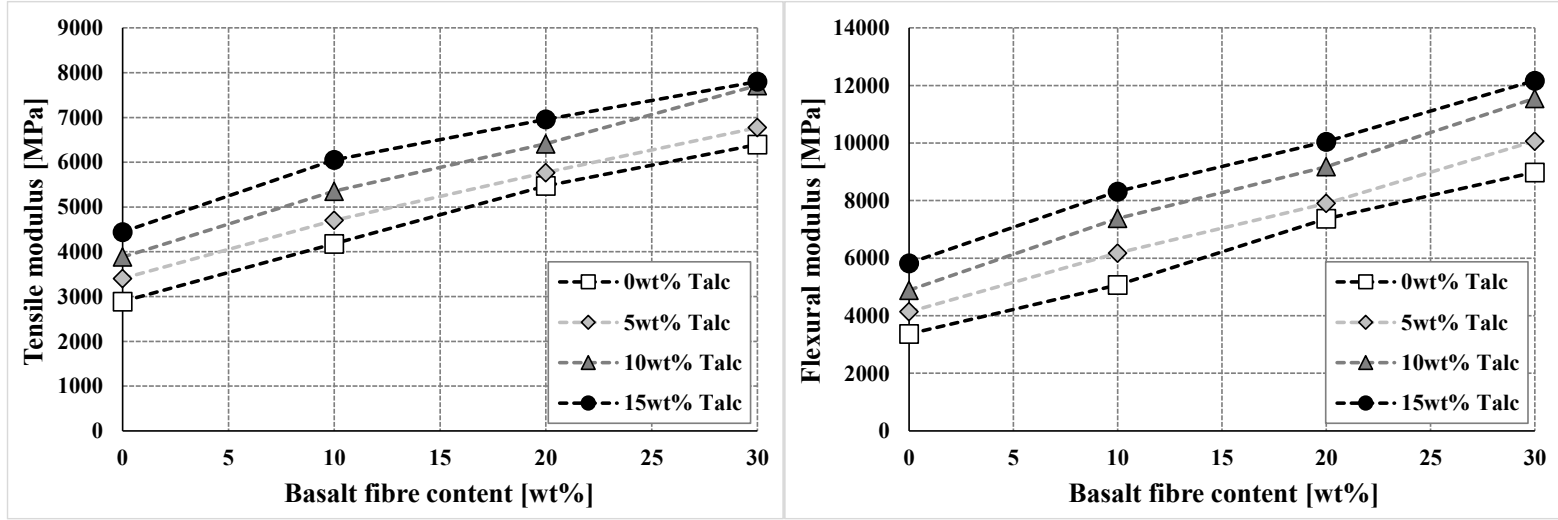

Fig. 2. Tensile (left) and flexural (right) modulus of the basalt reinforced and talc filled PLA composites

In case of impact properties, both basalt and talc significantly increased unnotched Charpy impact strength separately (Fig. 3.).

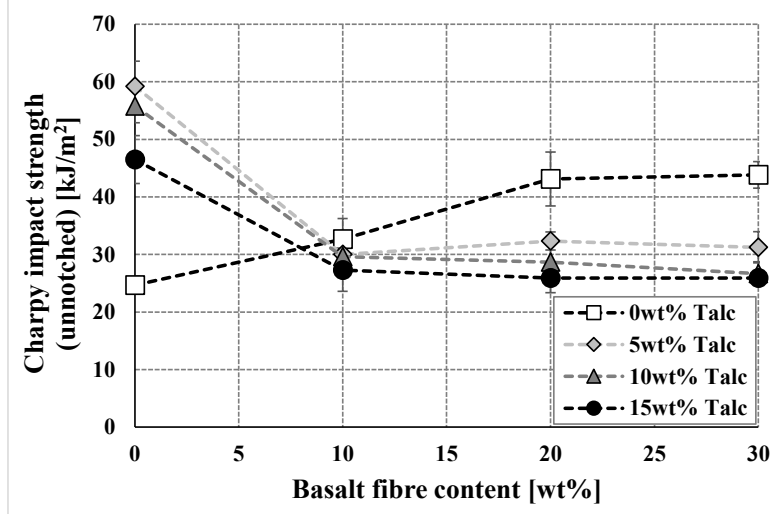

Fig. 3. Unnotched Charpy impact strength of the basalt reinforced and talc filled PLA composites

By adding $20 \mathrm{wt} \%$ of basalt fibres or $5 \mathrm{wt} \%$ of talc the impact strength increased to $43 \mathrm{~kJ} / \mathrm{m}^{2}$ and $59 \mathrm{~kJ} / \mathrm{m}^{2}$ respectively, from the original value of pristine PLA of $25 \mathrm{~kJ} / \mathrm{m}^{2}$. Unfortunately, when basalt and talc were used at the same time, a significant negative cross-effect was found and thus the impact strength of the $20 \mathrm{w} \%$ basalt and $5 \mathrm{wt} \%$ talc content PLA composite was found to be only $32 \mathrm{~kJ} / \mathrm{m}^{2}$. The adhesion between PLA and basalt fibres was investigated by using SEM (Fig. 4.).
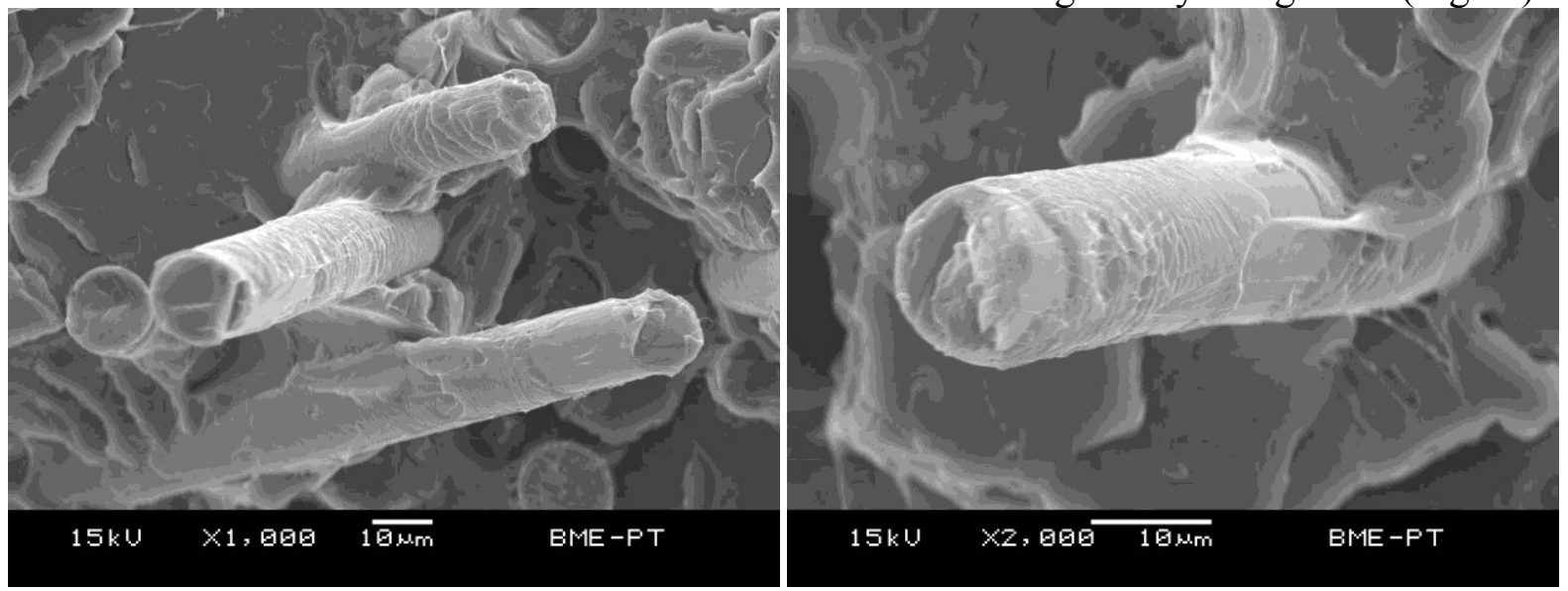

Fig. 4. Unnotched Charpy impact strength of the basalt reinforced and talc filled PLA composites 
It is visible that there was excellent adhesion found between the PLA and the basalt fibres, which is manifested in a PLA layer that developed on the surface of the basalt fibres as well as the absence of any gap at the root of the fibre and the PLA.

The next step in the research was to explore the effect of the basalt fibres and talc on the crystallization and HDT of PLA. PLA has very slow crystallization kinetics, which is manifested in its low level of crystallinity, especially, when high cooling rate melt processing technologies are used like injection moulding. In this way, an injection moulded PLA product becomes practically amorphous with only a few \% of crystallinity and thus transparent during processing. Since low crystallinity (and low $\mathrm{T}_{\mathrm{g}}$ ) also results in low HDT, thus the main goal was to increase the level of crystallinity as much as possible. To do so, unconventional mould temperature was used. First, for reference, $20^{\circ} \mathrm{C}$ cold mould was used, which is a common mould temperature for processing PLA due to its $\mathrm{T}_{\mathrm{g}}$ around $60^{\circ} \mathrm{C}$. Also, the uncommon hot mould temperature of $90^{\circ} \mathrm{C}$ was used to be able to induce crystallization, which mould temperature is eventually higher than the $\mathrm{T}_{\mathrm{g}}$ of PLA. The hot mould temperature not only decreases the cooling rate and gives better opportunity for PLA to crystallize during cooling, but also, by increasing cooling time, the PLA part could be crystallized or annealed within the mould to the desired level of crystallinity. In this case, if too low cooling (inmould-annealing) time is used, than the part will be distorted during demoulding due to the still too low crystallinity not providing enough stiffness at this elevated temperature. If the annealing time was enough, than the developed crystalline structure gives the part enough stiffness to be properly demoulded. To keep the comparability, only those composites (produced by using $90^{\circ} \mathrm{C}$ hot mould) were accepted for further analysis, which could be produced within the same cycle (cooling) time as for the $20^{\circ} \mathrm{C}$ mould temperature. After injection moulding, the crystallinity of the specimens were analysed (Fig. 5.). As it can be seen, when $20^{\circ} \mathrm{C}$ cold mould temperature was used, crystallinity was rather insensitive to the increase of basalt fibre content in case of $0-10 \mathrm{wt} \%$ talc content $(5-7 \%)$.
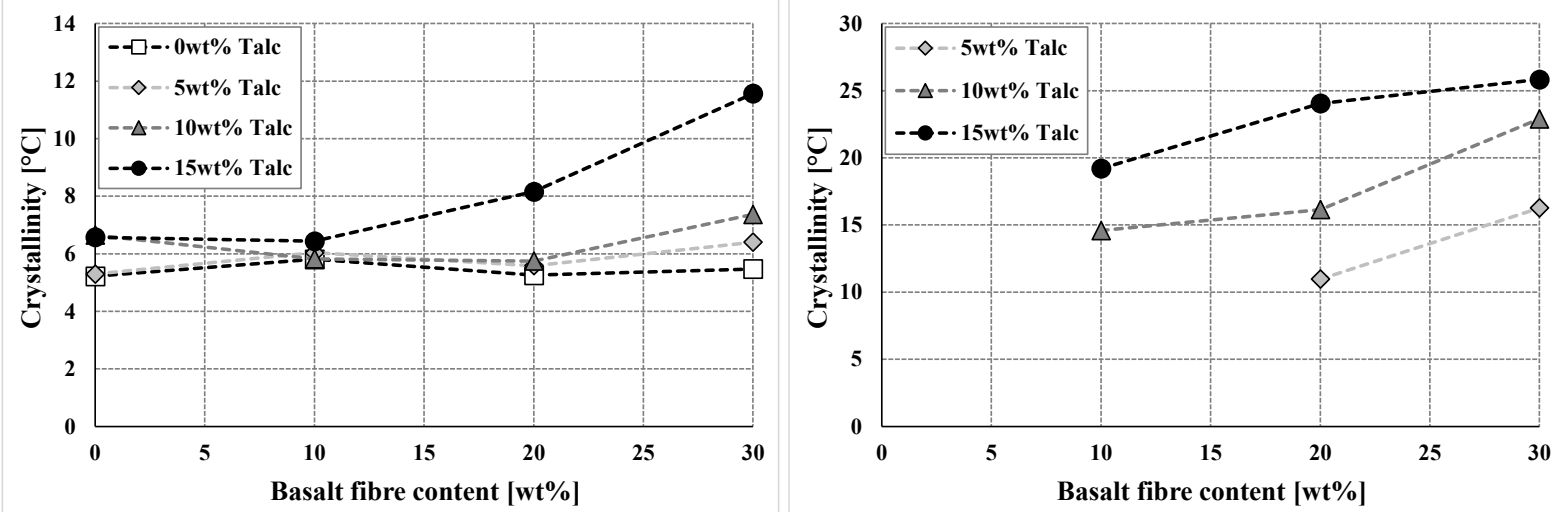

Fig. 5. Crystallinity of the basalt reinforced and talc filled PLA composites injection moulded into $20^{\circ} \mathrm{C}$ (left) and $90^{\circ} \mathrm{C}$ (right) mould

Nevertheless, when talc content reached $15 \mathrm{wt} \%$, the increase in basalt fibre content increased crystallinity up to $12 \%$. This value however, is still rather insignificant compared to the maximum crystalline level of around $45-50 \%$, meaning that low mould temperature and thus high cooling rate quenches the effect of nucleating agents. When $90^{\circ} \mathrm{C}$ hot mould temperature was used, all the specimens without talc content as well as the $5 \mathrm{wt} \%$ talc and $10 \mathrm{wt} \%$ basalt fibre content were rejected from further analysis due to still soft specimens during demoulding. Nevertheless, for the rest of the specimens, the $60 \mathrm{sec}$ of cooling time was enough for proper demoulding. For these specimens, crystallinity was found to increase with both increasing basalt fibre and talc content, meaning that not only talc, but also basalt fibres had nucleating ability on PLA, mainly developing transcrystalline structure around the basalt fibres. Naturally, the composite with the most reinforcement and filler content, namely the composite with $30 \mathrm{wt} \%$ basalt and $15 \mathrm{wt} \%$ talc content reached the highest, $26 \%$ of crystallinity, which is more than the double compared to the same composite injection moulded into $20^{\circ} \mathrm{C}$ cold mould. Finally, the effect of crystallinity on the HDT values was analysed (Fig. 6.). 

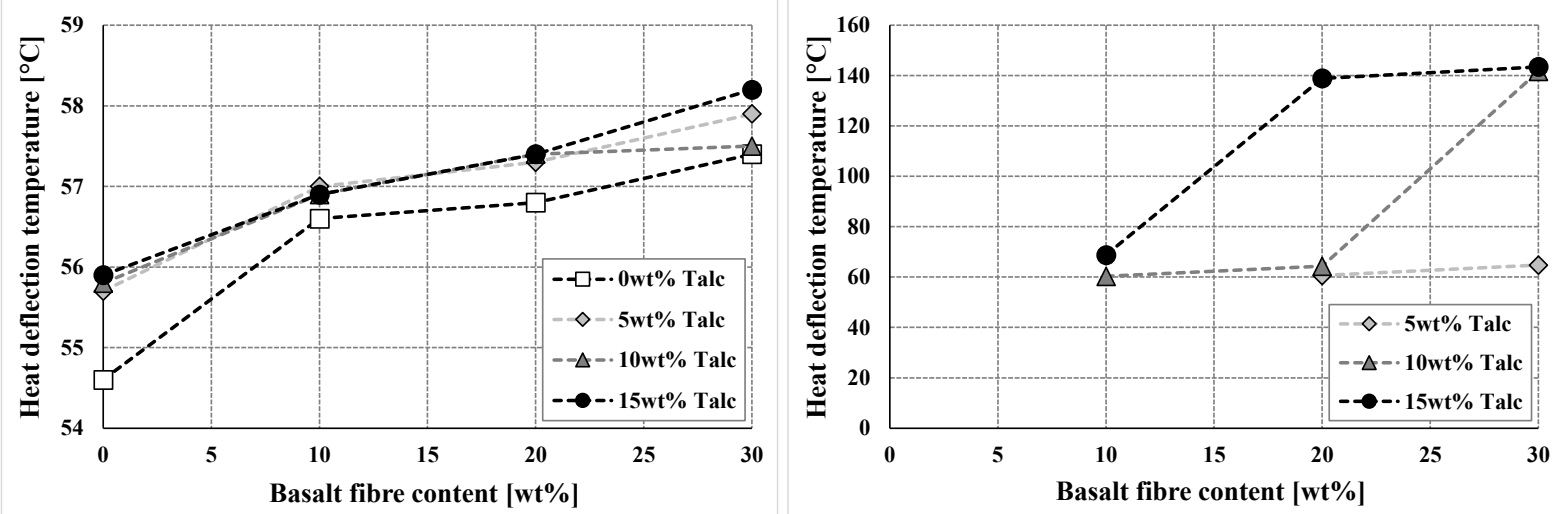

Fig. 6. Heat deflection temperature of the basalt reinforced and talc filled PLA composites injection moulded into $20^{\circ} \mathrm{C}$ (left) and $90^{\circ} \mathrm{C}$ (right) mould

In case of $20^{\circ} \mathrm{C}$ cold mould temperature, neither the basalt fibres, nor the developed crystalline structure was enough to significantly increase the HDT values. The maximum improvement achieved in HDT by using this mould temperature was around $3{ }^{\circ} \mathrm{C}$. At the same time, when $90^{\circ} \mathrm{C}$ hot mould was applied, HDT could be improved significantly, from $55^{\circ} \mathrm{C}$ (pristine PLA) even up to $144^{\circ} \mathrm{C}$. This was caused by the positive cross-effect of the stiffness increasing effect of basalt fibres and the developed crystalline structure. Latter is, in turn caused by the lower cooling rate of the $90^{\circ} \mathrm{C}$ hot mould as well as the nucleating ability of talc and basalt fibres.

\section{Summary}

In our work the renewable resource based and inherently biodegradable polymer, Poly(Lactic Acid) (PLA) was reinforced with mineral basalt fibres and filled with talc in order to develop an injection moulded, natural composite with high mechanical properties and improved heat deflection temperature for engineering applications. $0,10,20$ and $30 \mathrm{wt} \%$ of basalt fibres as well as $0,5,10$ and $15 \mathrm{wt} \%$ of talc was used for composite preparation by using the conventional extrusion and injection moulding processing techniques. It was found that basalt fibres linearly increase both tensile and flexural strength up to $20 \mathrm{wt} \%$ basalt fibre content, but above, fibre breakage becomes more dominant. Unfortunately, there was negative cross-effect found between the basalt fibre and the talc content for all of the measured strength values including tensile, flexural and Charpy impact strength values. It was proved that both talc and basalt act as nucleating agents on PLA and could be effectively used to increase the crystallinity of the injection moulded products. The effect of mould temperature was also investigated on the crystallinity and heat deflection temperature (HDT) of the composites, and it was demonstrated that for the PLA commonly used $20^{\circ} \mathrm{C}$ mould temperature quenches the nucleating effect of talc and basalt, only allowing to develop 12\% of crystallinity (in case of $30 \mathrm{wt} \%$ basalt and $15 \mathrm{wt} \%$ talc content composite). On the contrary, when the unconventional $90^{\circ} \mathrm{C}$ mould temperature was used, the crystallinity could be improved up to $26 \%$. As the result, the HDT significantly improved from $55^{\circ} \mathrm{C}$ (pristine PLA) even up to $144^{\circ} \mathrm{C}$ due to the positive cross-effect of the stiffness increasing effect of basalt fibres and the developed crystalline structure. Accordingly, in our research it was possible to develop an injection moulded, PLA based composite with natural reinforcements and fillers suitable for engineering applications due to its high tensile and flexural strength (106 $\mathrm{MPa}$ and $165 \mathrm{MPa})$, high tensile and flexural stiffness $(7.8 \mathrm{GPa}$ and $12.2 \mathrm{GPa})$ respectively, as well as high $\mathrm{HDT}\left(144^{\circ} \mathrm{C}\right)$.

\section{Acknowledgement}

This paper was supported by the János Bolyai Research Scholarship of the Hungarian Academy of Sciences. This publication was supported by the Italian-Hungarian and the Mexican-Hungarian bilateral agreement of the Hungarian Academy of Sciences. This work was supported by the 
Hungarian Scientific Research Fund (OTKA K105257). This work is connected to the scientific program of the "Development of quality-oriented and harmonized R+D+I strategy and functional model at BME" project. This project is supported by the New Széchenyi Plan (Project ID: TÁMOP4.2.1/B-09/1/KMR-2010-0002). The work reported in this paper has been developed in the framework of the project "Talent care and cultivation in the scientific workshops of BME" project. This project is supported by the grant TÁMOP - 4.2.2.B-10/1-2010-0009. The authors thank Arburg Hungária Kft. for the Arburg Allrounder 370S 700-290 injection moulding machine, Lenzkes $\mathrm{GmbH}$ for the clamping tool system and Piovan Hungary Kft. for their support.

\section{References}

[1] R. Chandra, R. Rustgi, Biodegradable polymers, Prog. Polym. Sci. 23 (1998) 1272-1335.

[2] L. T. Lim, R. Auras, M. Rubino, Processing technologies for poly(lactic acid), Prog. Polym. Sci. 33 (2008) 820-852.

[3] E. Bodros, I. Pillin, N. Montrelay, C. Baley, Could biopolymers reinforced by randomly scattered flax fibre be used in structural applications?, Compos. Sci. Technol. 67 (2007) 462470.

[4] V. Fiore, T. Scalici, G. Di Bella, A. Valenza, A review on basalt fibre and its composites, Compos. Part B-Eng. 74 (2015) 74-94.

[5] T. Tábi, P. Tamás, J. G. Kovács, Chopped basalt fibres: A new perspective in reinforcing poly(lactic acid) to produce injection moulded engineering composites from renewable and natural resources, Express Polym. Lett. 7 (2013) 107-119.

[6] T. Tábi, A. Z. Égerházi, P. Tamás, T. Czigány, J. G. Kovács, Investigation of injection moulded poly(lactic acid) reinforced with long basalt fibres, Compos. Part A-Appl. S. 64 (2014) 99-106.

[7] T. Czigány, J. G. Kovács, T. Tábi, Basalt fiber reinforced poly(lactic acid) composites for engineering applications, 19th International Conference on Composite Materials (ICCM19), CD proceeding, $8 \mathrm{p}$.

[8] S. Saeidlou, M. A. Huneault, H. Li, C. B. Park, Poly(lactic acid) crystallisation, Prog. Polym. Sci. 37 (2012) 1657-1677.

[9] D. Battegazzore, S. Bocchini, A. Frache, Crystallisation kinetics of poly(lactic acid)-talc composites, Express Polym. Lett. 5 (2011) 849-858.

[10] A. M. Harris, E. C. Lee, Improving mechanical performance of injection molded PLA by controlling crystallinity, J. Appl. Polym. Sci. 107 (2008) 2246-2255. 